JIOM Nepal. Volume 41 Number 3. December 2019, page 78-82.

\title{
Knowledge Regarding Antibiotic Use, its Resistance and Consequences among Higher Secondary Students in Private Schools of Kathmandu Valley
}

\author{
Satish K Deo ${ }^{1}$, Naveen Gautam², Siddinath Gyawali², Deepti Shrestha ${ }^{3}$, Shikha Yadav \\ ${ }^{1}$ Department of Clinical Pharmacology, Maharajgunj Medical Campus, ${ }^{2}$ Maharajgunj Medical Campus, Institute \\ of Medicine, Maharajgunj, Kathmandu, ${ }^{3}$ Department of Pharmacology, Nepal Medical College and Teaching \\ Hospital, Jorpati, Kathmandu, ${ }^{4}$ Alliance Against Antimicrobial Resistance, Nepal
}

\section{Corresponding author:}

Satish Kumar Deo, BDS, MD

Department of Clinical Pharmacology, Maharajgunj Medical Campus, Institute of Medicine, Maharajgunj, Kathmandu Email: satish.deo@iom.edu.np

Submitted : November 10, 2019

Accepted : December 2, 2019

\begin{abstract}
\section{Introduction}

The lack of awareness on the appropriate use of antibiotics, its dose and duration is one of the leading causes of global antimicrobial resistance (AMR). AMR poses a growing threat to public health, as infections from resistant strains of microbes become increasingly difficult to treat, resulting in prolonged illness and greater risk of death. Hence, this study would be an important reference for determining the scope of the problem which will be essential for formulating and monitoring an effective response to antibiotic use and its problem of resistance.
\end{abstract}

\section{Methods}

A descriptive cross-sectional study was done among higher secondary level students from selected schools in Kathmandu valley. Baseline data was collected after a tutorial session through semi-structured questionnaires which was based on past researches and verified using expert consultation. Ethical consideration was maintained throughout the study. Descriptive statistics was used to find out the KAP level including knowledge score and attitude-practice score of the selected population.

\section{Results}

Among 465 participants conducted in our research, the overall average knowledge score of the participants was found to be $73.3 \%$ while the attitude-practice score was $60.53 \%$. It was found that $80.86 \%$ of the participants had heard the term "antibiotic resistance". The knowledge score percentage among the students of grade 10 and 11 had no significant difference $(p$ value $=0.592)$.

\section{Conclusion}

Our study concludes that if topics like antibiotics and their judicial use is well covered in school curriculum, it can produce measurable change in knowledge, attitude and practice level of the students.

Keywords: Attitude, antibiotics, antimicrobial resistance, knowledge, practice

\section{INTRODUCTION}

T he lack of awareness on the appropriate use of antibiotics, its dose and duration including self-medication is one of the leading causes of global antimicrobial resistance (AMR). ${ }^{1}$ Therefore, strategies that encourage antimicrobials to be used more responsibly and less often are needed to safeguard human health to reduce substantial economic and clinical burden. This includes awareness campaigns targeting the public to raise the profile of the issue and induce societal and cultural change. ${ }^{2}$ Higher secondary level students, in their formative level of schooling are the most malleable group to adopt practices such as the use 
of antibiotics irrationally without proper supervision and care. Therefore, targeting this demography is crucial to bring positive attitude about the use of antibiotics amongst themselves, their family and the society as a whole. Identifying the variables that affect the behavior of adolescents towards use of antibiotics is thus substantial.

\section{METHODS}

The study was conducted over a period of 3 months from July 2019 to October 2019. The questionnaire structure and content was designed taking references from various similar literatures. They were adapted for our settings by the study team. The questionnaire was pilot tested in a nearby private higher secondary school and was finalized after expert consultation. Five different private higher secondary schools inside Kathmandu valley were chosen based on convenience sampling. The questionnaire consisted of single answer responses, multiple answer responses and 5-point Likert scaling type questions. Sample size for the study was calculated from Raosoft at 95\% confidence interval, $5 \%$ margin of error, population size of 20000 (estimate made considering about 100 higher secondary schools in Kathmandu each with 200 science students each). The students were first tutored by pertinent experts in the field before they were provided with the questionnaires. Data was collected by distributing self-administered questionnaires after taking informed expressed consent from the participants.

The questionnaire had two types of questions. The first type of question assessed the knowledge on the use, resistance of antibiotics and the consequences of antibiotic resistance. The second type included questions assessing their attitude and practice regarding antibiotics. The rest were designed to assess other variables such as perception and exposure. The respondents answered 16 different questions independently in 20 minutes following a tutorial class beforehand.

Responses for different questions were coded to facilitate data entry and data analysis for uniformity. Responses from the 5-point Likert scale questions were condensed into three categories: agree, neutral, and disagree. The data was entered in Excel 2019 and analyzed using 25.0 version of SPSS Statistics software.

For calculating knowledge score, we gave each correct answer a score of 1 while each wrong answers a score of 0 . Each question out of 6 knowledge questions in the knowledge section only had one correct answer and at least one wrong answer. This way, a respondent could score a maximum of 6 and a minimum of 0 in this section. For calculating attitude and practice score, a score of 1 was given to "disagree," a score of 2 was given to "neutral," and a score of 3 was given to "agree." All the questions were positively framed. There was one question for attitude and one for practice, therefore, the maximum scores for attitude and practice equaled to 4 while the minimum score equaled to 1 . The other questions were perception based. The total knowledge score (K-score), attitude-practice score (AP-score) were calculated using MS Excel 2019. In addition, the total percentages of knowledge score and attitudepractice score of students were evaluated and the corresponding P-value was calculated using two sample t- test in SPSS, to see whether the gap in KAP scores among grade 11 and grade 12 students was statistically significant.

\section{RESULTS}

Our study included 465 participants from five private higher secondary level schools inside Kathmandu valley. The mean age of the respondents was 14.26 years. More than half of them $(59.5 \%)$ were males. Among several sets of questions asked, $35.27 \%$ of respondents didn't remember the last time they took antibiotics while $20 \%$ responded to have taken them in the last month. Only a marginal proportion $(5.16 \%)$ responded to have never consumed antibiotics. About one third (35.91\%) of the participants took antibiotics within last one year while $23.87 \%$ responded to have not taken any in that interval. Among those who consumed antibiotics, $65.8 \%$ took them under doctor's prescription.

On the basis of six questions to assess the knowledge of antibiotic resistance, the average knowledge score ( $k$ score) was found to be $73.3 \%$. The frequency of respondents who correctly answered that antibiotics were used to treat bacterial infections was 241 (51.83\%).We also found that $74.41 \%$ correctly responded about the intake of antibiotics to be stopped only after the completion of full course as directed. The respondents who thought that antibiotics given to their family or friends should not be taken without medical consultation even under similar illnesses was $84.52 \%$. Out of the total respondents, $80.86 \%$ correctly answered that antibiotic resistant infections could make medical procedures like surgery, organ transplants and cancer treatments much more dangerous. The respondents who believed that many infections are becoming increasingly resistant owing to rampant usage of 
Table 1. Assessment of knowledge

\begin{tabular}{|c|c|}
\hline Questions & Frequency (\%) \\
\hline $\begin{array}{l}\text { Antibiotics are used to treat } \\
\text { - Viral infections } \\
\text { - Bacterial infections } \\
\text { - Parasitic infections } \\
\text { - All type of viral, bacterial and } \\
\text { parasitic infection } \\
\text { - Don't know } \\
\text { - Missing }\end{array}$ & $\begin{array}{c}39(8.39) \\
241(51.83) \\
2(0.43) \\
121(26.02) \\
40(8.60) \\
22(4.73)\end{array}$ \\
\hline $\begin{array}{l}\text { When should intake of } \\
\text { antibiotics be stopped? } \\
\text { - When they felt better } \\
\text { - Whey they had taken all the } \\
\text { drugs as directed } \\
\text { - Don't know }\end{array}$ & $\begin{array}{c}76(16.34) \\
346(74.41) \\
43(9.25)\end{array}$ \\
\hline $\begin{array}{l}\text { Is it okay to use antibiotics given } \\
\text { by friends/family? } \\
\text { - Yes } \\
\text { - No } \\
\text { - Don't know }\end{array}$ & $\begin{array}{c}24(5.16) \\
393(84.52) \\
48(10.32)\end{array}$ \\
\hline $\begin{array}{l}\text { Statements } \\
\text { - Antibiotic-resistant infections } \\
\text { could make medical } \\
\text { procedures like surgery, } \\
\text { organ transplants and cancer } \\
\text { treatment much more } \\
\text { dangerous } \\
\text { - Many infections are becoming } \\
\text { increasingly resistant (difficult } \\
\text { to treat) by antibiotics } \\
\text { - Resistant bacteria can spread } \\
\text { from person to person }\end{array}$ & $\begin{array}{l}388(83.44) \\
340(73.12)\end{array}$ \\
\hline
\end{tabular}

antibiotics was $83.44 \%$. Around 3/4th $(73.11 \%)$ believed that resistant bacteria could spread from person to person. The K-score percentage of grade 11 and 12 were found to be $74.15 \%$ and $72.5 \%$ respectively with a p-value of 0.592 which shows that the difference is not significant.

The term "antibiotic resistance" was heard by $80.86 \%$ of the respondents. However, only $32.69 \%$ had heard the term "superbugs". They responded to have heard the term "antibiotic resistance" respectively from doctor/nurse $(40.86 \%)$, family/ friends/social media (11.4\%) and only a few $(4.73 \%)$ couldn't remember the source. More than half of the respondents $(57.42 \%)$ agreed that farmers should not be promoted to use antibiotics in food producing animals. At a response rate of $77.85 \%$, only $40.33 \%$ of the participants had heard about post antibiotic era. Also, at a response rate
Table 2. Assessment of attitude and practice

\begin{tabular}{lc}
\hline \multicolumn{1}{c}{ Questions } & Frequency (\%) \\
\hline Attitude : People should use & \\
antibiotics only when they are & \\
prescribed by a doctor or nurse & \\
- Agree & $450(96.77)$ \\
- Neutral & $10(2.15)$ \\
- Disagree & $5(1.07)$ \\
Practice : Did you take a doctor's & \\
prescription during illness? & \\
- Yes & $306(65.80)$ \\
- No & $62(13.33)$ \\
- Don't remember & $97(20.86)$ \\
\hline
\end{tabular}

of $86.2 \%, 60.8 \%$ had heard about one health concept.

The overall attitude-practice (AP) percentage was found to be $60.53 \%$. The respondents who believed that antibiotic resistance occurred because of using antibiotics without physician's prescription was $56.77 \%$ and those who believed that it occurred by using antibiotics when they are not necessary was $56.55 \%$. Out of total respondents, $42.8 \%, 18.7 \%$ and $15.9 \%$ responded the common side effects of antibiotics as headache, nausea/vomiting and rashes/ allergic reactions respectively while $29.9 \%$ didn't know about the side effects.

At a response rate of $80 \%$, the responses to questions assessing their understanding on the consequences of antibiotic resistance respectively were longer duration of illness (38.71\%); increased burden on health system (28.76\%); higher mortality (23.39\%); longer treatment $(15.86 \%)$ and treatment with expensive drugs (10.32\%).

\section{DISCUSSION}

Our study aimed to assess the knowledge, attitude, and practice (KAP) of students regarding antibiotics, resistance and its consequences in selected private higher secondary schools of Kathmandu valley. Among the respondents, $35.27 \%$ didn't remember the last time they took antibiotics and about one third $(35.91 \%)$ of the participants took antibiotics within last one year unlike the survey report by WHO which reported that $65 \%$ of the respondents across 12 countries reported having taken antibiotics within the past six months. (3) Among those who had consumed antibiotics, $65.8 \%$ took them under doctor's prescription. Whereas, in contrast to this finding, is the study report by Pereko, Lubbe \& Essack where 
$82 \%$ of the respondents mentioned pharmacy as a source of taking antibiotics. ${ }^{4}$

On the basis of six questions set to assess the knowledge of antibiotic resistance, the average k-score percentage was found to be $73.3 \%$. Among the total respondents, $51.83 \%$ correctly answered that antibiotics were used to treat bacterial infections, whereas in a study report by Kandelaki, Lundborg \& Marrone it was seen that $55 \%$ of the respondents believed in antibiotics to be beneficial against viruses. ${ }^{5} \mathrm{~A}$ total of $48.6 \%$ responded that not completing the full course of antibiotics is one of the causes of antibiotic resistance. This finding agrees with the study done among Chinese in Hong Kong where $75.1 \%$ supported the statement that incomplete courses of antibiotics would lead to undesirable consequences. ${ }^{6}$

Our study found that $84.52 \%$ answered that the antibiotics prescribed to their family or friends should not be taken without medical consultation even if the illnesses resemble. A contrast to our study can be seen in a survey by WHO (2015) where $25 \%$ of respondents across 12 countries responded that it is acceptable to use antibiotics given to a friend, family member, as long as they were used to treat the same illness. ${ }^{7}$

Our study revealed that $80.86 \%$ of the students had heard the term "antibiotic resistance". This finding is in line with the study done in Palestine which showed that $65.0 \%$ of respondents had heard the term. ${ }^{8}$

Out of total respondents, $42.8 \%, 18.7 \%$, and $15.9 \%$ responded to the common side effects of antibiotics as headache, nausea/vomiting and rashes/ allergic reactions respectively. Only 29.9\% didn't know about the side effects. Among those who responded, $26.2 \%$ of the respondents in a study by Deo et al had mentioned nausea and vomiting as the major side effects. ${ }^{9}$ At a response rate of $80 \%$, the responses on the consequences of antibiotic resistance respectively were longer duration of illness (38.71\%); an increased burden on the health system (28.76\%); higher mortality (23.39\%); longer treatment (15.86\%) and treatment with expensive drugs (10.32\%). This is similar to what was reported on awareness study done regarding the impact of antimicrobial resistance by Eliopoulos, Cosgrove \& Carmeli and Kim, Moon, Kim which stated that there is a direct correlation of hospital length of stay and the cost, future length of stay, and mortality. ${ }^{10,11}$ All the results we explored are found to be satisfactory compared to other similar literatures, which may be due to the fact that a tutorial class was already taken beforehand implying that if this topic is properly addressed in their curriculum, it wouldn't be a difficult thing to grasp into.

\section{CONCLUSION}

Our study concludes that the higher secondary level students can understand the burden, impact, and consequences of antibiotic resistance as well as get oriented to bring about positive changes in their attitude and practice if they are well tutored. Thus, it might be substantial to add coverage on antibiotics, its resistance and the consequences in the curriculum itself, right from the higher secondary-school level to help delay the post antibiotic era.

\section{CONFLICT OF INTEREST}

None declared.

\section{REFERENCES}

1. Kotwani A, Wattal C, Joshi PC, Holloway K. Knowledge and perceptions on antibiotic use and resistance among high school students and teachers in New Delhi, India: A qualitative study. Indian J Pharmacol [Internet]. 2016;48(4):365-71.

2. King S, Exley J, Taylor J, Kruithof K, Larkin J, Pardal M. Antimicrobial Stewardship: The Effectiveness of Educational Interventions to Change RiskRelated Behaviours in the General Population: A Systematic Review. Rand Heal Q. 2016 Jan;5(3):2.

3. Asokan $G$ V , Ramadhan $T$, Ahmed $E$, Sanad $H$. WHO Global Priority Pathogens List: A Bibliometric Analysis of Medline-PubMed for Knowledge Mobilization to Infection Prevention and Control Practices in Bahrain. Oman Med J. 2019 May;34(3):184-93.

4. Pereko DD, Lubbe MS, Essack SY. Public knowledge, attitudes and behaviour towards antibiotic usage in Windhoek, Namibia. South African J Infect Dis. 2015 Nov 13;30(4):134-7.

5. Kandelaki K, Lundborg CS, Marrone G. Antibiotic use and resistance: a cross-sectional study exploring knowledge and attitudes among school and institution personnel in Tbilisi, Republic of Georgia. BMC Res Notes. 2015 Sep;8:495.

6. Wun YT, Lam TP, Lam KF, Ho PL, Yung WHR. The public's perspectives on antibiotic resistance and abuse among Chinese in Hong Kong. Pharmacoepidemiol Drug Saf. 2013 Mar;22(3):2419.

7. WHO. Antibiotic resistance: Multi-country public awareness survey. WHO [Internet]. 2016 [cited 2019 Nov 14]; Available from: https:// www.who.int/drugresistance/documents/ baselinesurveynov2015/en/\#.Xc1INrjC434. mendeley

8. Abu Taha A, Abu-Zaydeh AH, Ardah RA, Al-Jabi 
SW, Sweileh WM, Awang R, et al. Public Knowledge and Attitudes Regarding the Use of Antibiotics and Resistance: Findings from a Cross-Sectional Study Among Palestinian Adults. Zoonoses Public Health. 2016 Sep;63(6):449-57.

9. Deo S, Rijal S, K.C T. Public awareness regarding the use and resistance of antibiotics: A crosssectional study among Nepalese adults in
Kathmandu valley. J Kathmandu Med Coll. 2018 May 5;6:96-101.

10. Cosgrove SE, Carmeli Y. The impact of antimicrobial resistance on health and economic outcomes. Clin Infect Dis. 2003 Jun;36(11):1433-7.

11. Kim SS, Moon S, Kim EJ. Public knowledge and attitudes regarding antibiotic use in South Korea. J Korean Acad Nurs. 2011 Dec;41(6):742-9. 